\title{
STUDI PENGELOLAAN ZAKAT PROFESI PADA BADAN AMIL ZAKAT (BAZ)
}

\author{
Muhammad Ardian', \\ ${ }^{1}$ Mahasiswa Prodi Hukum Ekonomi Syariah FAI Unismuh Makassar \\ ${ }^{1}$ Dosen Prodi Hukum Ekonomi Syariah FAI Unismuh Makassar
}

\begin{abstract}
Abstrak
Penelitian ini bertujuan untuk mengetahui Studi Pengelolaan Zakat Profesi Pada Badan Amil Zakat Makassar. Penelitian ini merupakan upaya untuk mengetahui tentang Studi Pengelolaan Zakat Profesi Pada Badan Amil Zakat Makassar.. Fokus penelitian yang ingin dijawab melalui penelitian ini adalah (1) Bagaimana sistem pengelolaan zakat profesi di Badan Amil Zakat Makassar?, (2)Bagaimana Hukum Zakat Profesi?,(3) Bagaimana Pemenafaatan dana zakat ?. Untuk menjawab pertanyaan tersebut maka penelitian yang digunakan adalah penelitian lapangan (Field Research). Penelitian menggunakan pendekatan kualitatif dan kuantitatif dengan teknik data melalui observasi, wawancara, kusioner dan dokumentasi. Metode analisis datanya menggunakan teknik analisis Kuantitatif dengan menggunakan Program Smart PLS.

Kesimpulan yang dihasilkan pada penelitian ini adalah pengambilan zakat profesi di Badan Amil Zakat Makassar dari UPZ di setiap bulannya. Kemudian dana yang diserahkan kepada BAZ dan didistribusikan sesuai dengan programprogram yang sudah ada. Program diantaranya, Pembinaan Agama,Pelatiahan sholat jenazah, bantuan kepada guru TK/TPA, bantuan muallaf, pelayanan pendidikan/ Beasiswa, bantuan kesehatan, dan bantuan sosial. bantuan tersebut yang masuk tujuannya untuk peningkatan mutu.
\end{abstract}

Kata Kunci : Pengelolaan, Zakat Profesi

\section{Abstract}

This study aims to determine the Study of Zakat Management Profession At Amil Zakat Agency Makassar. This research is an effort to know about Zakat Profession Management Study at Amil Zakat Agency of Makassar. The research focus that want to be answered through this research is (1) How is the management system of zakat profession in Badan Amil Zakat Makassar ?, (2)) How Zakat Law Profession ?, (3) How to Fulfill the Zakat Fund ?. To answer the question then the research used is field research (Field Research). The research used qualitative and quantitative approach with data technique through observation, interview, questioner and documentation. The method of data analysis using Quantitative analysis technique using Smart PLS Program.

The conclusion resulted in this research is the taking of zakat profession at Badan Amil Zakat Makassar from UPZ in every month. Then the funds are submitted to the $B A Z$ and distributed in accordance with the existing programs. Programs such as, Religious Coaching, Counselor prayer, assistance to Kindergarten / TPA teachers, Muallaf help, education services / Scholarships, health assistance, and social assistance. such assistance that enters its objective for quality improvement.

Key Word: Management, Profession Zakat

\section{A. PENDAHULUAN}

Kedudukan zakat ini sejajar dengan kedudukan sholat. Dalam Al- 
Qur'an, tidak kurang dari 28 ayat Allah menyebutkan perintah sholat dengan pemerintah zakat dalam satu ayat sekaligus. Diantaranya dalam surat, yang artinya :

"Dirikanlah sholat, tunaikan zakat, serta ruku'lah bersama orangorang yang ruku" (QS AlBaqarah: 43)

Kewajiban zakat merupakan salah satu jalan atau sarana untuk tercapainya keselarasan dan kemantapan hubungan antara manusia dengan Allah SWT serta hubungan manusia dengan manusia lainnya. Dengan kewajiban zakat, selain membina hubungan dengan Allah SWT sekaligus memperdekat hubungan kasih sayang antara sesama manusia, yaitu adanya saling tolong menolong dansaling membantu antara sesama manusia. Kewajiban zakat merupakan salah satu upaya untuk mewujudkan terbentuknya masyarakat yang baldatun tayyibatun warrabun ghaffar, yaitu masyarakat yang baik dibawah meungan keampunan dan keridhoan Allah SWT.

Di Indonesia, pengelola zakat diatur berdasarkan Undang-Undang No. 23 Tahun 2011 Tentang Pengelola Zakat dan Peraturan Pemerintah Republik Indoensia No 14 Tahun 2014 tentang Pelaksanaan Undang-Undang Republik Indonesia No 23 tahun 2011 tantang Pengelolaan Zakat

Dalam Bab Tentang Sanksi (Bab VII Pelanggaran terhadap ketentuan sebagimana dimaksud dalam pasal 19, pasal 23 ayat (1), pasal 28 ayat (2) dan ayat (3), serta pasal 29 ayat (3) di kenaikan sanksi administrasi yang berupa :

1. Peringatan tertulis

2. Penghentian sementara dari kegiatan : dan / atau

3. Pencabutan izin

Permasalahan dalam penelitian ini adalah, zakat profesi terhadap BAZ, pengaruh zakat profesi terhadap pengelolaan zakat, pengaruh BAZ terhadap pengelolaan zakat.

Menurut (Qardawi Yusuf 1973 : 275), pekerjaan yang menghasilkan yang ada dua macam. Pertama, pekerjaan yang dikerjakan sendiri tanpa tergantung kepada orang lain, berkat kecekatan tangan maupun otak. Penghasilan yang diperoleh dengan cara ini merupakan penghasilan profesional, seperti penghasilan seorang dokter insinyur, advokat, seniman dan lain-lain. Kedua, yaitu pekerjaan yang dikerjakan seorang buat pihak-pinak pemerintah, 
perusahaan, maupun perorongan ini yang menjadi sampel adalah para dengan memperoleh upah yang muzakki dan Pengelola Zakat sebagai memberikan, dengan tangan, otak, berikut : 1) Pegawai/staff yang berkerja ataupun kedua-duanya. Pengahasilan selama 1 tahun lebih, 2) Muzakki yang dari pekerjaan seperti itu berupa gaji, dari Badan Amil Zakat Kota Makassar. upah, ataupun honorium.

Data primer. Data primer Menurut (Majelis Tarjih diperoleh secara langsung melalui Muhammadiyah) Pada Musyawarah pembagian kusioner terhadap Nasional Tarjih XXV yang berlangsung responden, dalam hal ini muzakki, pada tanggal 3-6 Rabiul Akhir $1421 \mathrm{H}$ yang dipilih secara acak namun sesuai bertepatan dengan tanggal 5 - 8 Juli dengan kriteria yang telah ditetapkan 2000 M bertempat di Pondok Gede serta amil zakat dan pihak manajemen Jakarta Timur dan dihadiri oleh Badan Amil Zakat, dan observasi.Data anggota Tarjih Pusat. Lembaga ini skunder. Data ini dapat diperoleh pada intinya berpendapat bahwa Zakat melalui buku-buku ataupun jurnal dan Profesi hukumnya wajib. Sedangkan artikel yang relevan dengan nisabnya setara dengan 85 gram emas 24 karat. Ada pun kadarnya sebesar $2,5 \%$ pengelolaan zakat profesi Badan Amil Zakat, serta dokumentasi yang berasal dari Badan Amil Zakat.

\section{B. METODE PENELITIAN}

Metode penelitian yang digunakan dalam penelitian ini adalah penelitian Kualitatif dan Kuantitatif. Metode ini digunakan karena penelitian ini bertujuan untuk memberikan penjelasan mengenai Studi Pengelolaan Zakat Profesi Pada Badan Amil Zakat (BAZ).

Populasi dalam penelitian ini adalah muzakki dan pengelolaan zakat di Badan Amil Zakat Makassar yaitu sebanyak 32 orang. Dalam penelitian
Teknin pengumpulan data yang digunakan dalam penelitian ini adalah :1) Obesevasi atau pengamatan langsung terhadapa objek yang diteliti untuk mendapatkan gambaran yang jelas dan faktual di lapangan. Hasil pengamatan tersebut kemudian dicatat secara sistematik, 2) Kusioner yang dilakukan dengan menyebarkan data pertanyaan kepada amil zakat yang berkaitan dengan sistem pengelolaan Badan Amil Zakat SulSel Makassar. Kusioner dibuat dalam bentuk pilihan ganda den gan lima butir opsi jawaban 
untuk setiap pertanyaan. Skala kuantitatif mudah di ukur terhadap pengukuran yang digunakan adalah bagian pengeloaannya. Dari tingkat skala pengukuran likers dimana skor 5 pendapatan dapat dilihat apah suatu merupakan nilai tertinggi dan skor 1 program mampu menjalan sistemnya merupakan nilai terendah. 3) dengan baik dan benar.

Dokumentasi yang dilakukan melalui pengumpulan data dan dokumen perusahaan. Melalui dokumentasi, penelitian dapat mengenal budaya dan niai yang dianut oleh objek yang diteliti.

Dalam penelitian analisis data menggunakan pendekatan partial least Square (PLS). PLS adalah model persamaan Structural Equation Modeling (SEM) yang berbasis komponen atau varian. Menurut Ghozali (2006), PLS merupakan pendekatan alternatif yang bergeser dari pendekatan alternatif yang bergeser dara pendekatan SEM berbasis kovarian menjadi berbasis varian.

\section{Teknik Pengelolahan dan Anlisis data}

Data kuantitif yang di peroleh dari lapangan diolah dengan menggunakan tabel frekuensi yang digunakan untuk menganalisis sistem pengelolaan zakat. Peneliti ini menggunakan indikator pendapatan untuk melihat pengelolaan zakat yang di kelola oleh Badan Amil Zakat. Hal tersebut dilakukan karena indikator pendapatn

Setelah tahapan-tahapan di atas dilakukan, maka mikanismu selanjutnya adalah menganalisa masalah dari data-data yang telah dikumpulkan yang berkenaan dengan permasalahan yang di bahas, lalu disusun dan selanjutnya dianalisa, agar pembahasan tersebut sesuai dengan judul dan rumusan masalah.

Dalam skripsi ini, metode analisis data yang digunakan penelitian adalah metode kuantitatif yaitu penelitian pengukuran secara objektif yang Tujuan utama dari metodologi ini ialah menjelaskan suatu masalah tetapi menghasilkan generalisasi. Generalisasi ialah suatu kenyataan kebenaran yang terjadi dalam suatu realitas tentang suatu masalah yang di perkirakan akan berlaku pada suatu populasi tertentu. (Drs.Sumanto.M.A. , 1995)

Dalam penelitian analisis data menggunakan pendekatan partial least Square (PLS). PLS adalah model persamaan Structural Equation Modeling (SEM) yang berbasis 
komponen atau varian. Menurut pradictive relevance dan uji $\mathrm{t}$ serta Ghozali (2006), PLS merupakan signifikan dari koefisien parameter jalur pendekatan alternatif yang bergeser struktural.

dari pendekatan alternatif yang bergeser dara pendekatan SEM berbasis kovarian menjadi berbasis varian.

SEM yang berbasis kovarian umumnya mengudi kausalitas/teori sedangkan PLS lebih bersifat predictive model. PLS merupakan metode analisis yang powerfull (Ghozali, 2006), karena tidak didasarkan pada banyak asumsi. Misalkan, data harus terdistribusi normal, sampel tidak harus besar, selain dapat digunakan untuk mengkonfirmasi teriru, PLS juga digunakan untuk menjelaskan ada tidaknya hubungan antar laten. PLS dapat sekaligus mengenalisis konstruk yang dibentuk dengan indikator dengan indikator reflektif dan formatif.

\section{Model Struktural atau inner Model}

Inner model (inner relation, struktural model dan substantive theory) menggambarkan hubungan antara variabel laten berdasarkan pada teori substantif. Model struktural dievaluasi dengan menggunakan $\mathrm{R}$ Square untuk konstruk dependen, Stone-GeisserQ-square test untuk

\section{Model pengukuran atau Outer Model}

Convergent validity dari model pengukuran dengan model reflektif indikator dinilai berdasarkan korelasi antara itenm score/component score dengan construct score yang dihitung dengan PLS. Ukuran refleksi dikatakan tinggi jika berkorelasi lebih dari 0,70 dengan kosntruk yang ingin diukur. namun demikian untuk penelitian tahap awal daro pengembangan skala pengukuran nilai loading 0,5 sampai 0,60 dianggap cukup (Chin, 1998 dalam Ghozali 2006). Discriminant validity dari model pengukuran dengan refleksi indikator dinilai berdasarkan cross loading pengukuran dengan konstruk. Jika korelasi dengan item pengukuran lebih besar daripada ukuran kosntuk lainnya. Makan akan menunjukkan bahwa kosntruk laten memprediksi ukuran pada blok yang lebih baik daripada ukuran blok lainnya.

\section{HASIL PENELITIAN}

\section{Analisis Data}


Tehnik Pengumpulan data Convergent validity dari model dengan menggukan metode SEM pengukuran dengan refleksi indikator berbasis Partial Last Square (PLS) dinilai berdasarkan korelasi antara item Memerlukan 2 tahap untuk menilai Fit score/component score yang distimasi Model dari model penelitian (Ghozali, dengan software PLS. Ukuran Refleksi 2006). Tahap-tahap tersebut adalah Individual dikatakan tinggi jika sebagai berikut : berkorelasi lebih dari 0,70 dengan

\section{Menilai Outer Model}

Atau konstruk yang diukur. Namun menurut Measurement Model

Chin, 1998 ( dalam Ghozali, 2006) untuk penelitian terhadap awal dari

Terhadap tiga kriteria di dalam pengembangan skala pengukuran nilai penggunaan teknik analisis data leading 0,5 sampai 0,6 dianggap cukup dengan SmartPLS untuk outer model memadai. Dalam penelitian ini akan yaitu Convergent validity, Discriminant digunakan batas loading factor sebesar validity dan composite Reliability. 0,60.

Tabel C.1

Outer Loadings (Measurement Model)

\begin{tabular}{lll}
\hline Zakat Profesional & BAZ & Pengelolaan Zakat
\end{tabular}

\begin{tabular}{lll}
\hline PZ1 & & 0.824 \\
\hline PZ2 & & 0.687 \\
\hline PZ3 & & 0.789 \\
\hline BAZ1 & 0.750 & \\
\hline BAZ2 & 0.846 & \\
\hline ZP1 & & \\
\hline ZP2 & 0.704 & \\
\hline ZP3 & 0.879 & \\
\hline
\end{tabular}

Sumber: Pengelolahan data dengan PLS, 2015

Hasil pengelolaan dengan variabel pada awalnya Sudah menggunakan SmartPLS dapat dilihat memenuhi convergen validaty karena Tabel C.1 Nilai outer model atau sudah cukup banyak indikator yang korelasi antara konstruktur dengan 
memiliki nilai leading factor di atas Model mempunyai discriminant validity 0,60 . yang baik jika setiap nilai loading dari

\section{Discriminat Validity}

Discriminant validity dilakukan untuk memastikan bahwa setiap terhadap variabel latern lainnya. konsep dari masing variabel laten Hasilnya pengujian discriminant berbeda dengan variabel lainnya. diperoleh sebagai berikut:

Tabel C.2

Nilai Discriminant validity

(Cross Loading)

\begin{tabular}{lccr}
\hline & Zakat Profesi & BAZ & \multicolumn{2}{c}{$\begin{array}{c}\text { Pengelolaan } \\
\text { Zakat }\end{array}$} \\
\hline PZ1 & 0.024 & 0.208 & 0.824 \\
\hline PZ2 & -0.146 & 0.129 & 0.687 \\
\hline PZ3 & 0.007 & 0.163 & 0.789 \\
\hline BAZ1 & 0.220 & 0.750 & 0.110 \\
\hline BAZ2 & 0.241 & 0.846 & 0.221 \\
\hline ZP1 & 0.704 & 0.077 & 0.021 \\
\hline ZP2 & 0.879 & 0.152 & -0.033 \\
\hline ZP3 & 0.797 & 0.231 & -0.061
\end{tabular}

Sumber: Pengelolaan data dengan PLS, 2015

Dari Tabel C.2 dapat dilihat masing variabel latern masih nilai bahwa beberapa nilai loading factor loading factor yang tidak paling bersar untuk setiap indikator dari masing- dibandingkan nilai loading jika 
dihubungkan dengan variabel latern lainnya. Hal ini berarti bahwa setiap variabel latern belum memiliki pengukur yang berkorelasi tinggi dengan konstruk lainnya.

2. Mengevaluasi Reliability dan Avage Variance Extracted (AVE)
Kriteria validity dan reliabilitas juga dapat dilihat dari nilai reliabilitas suatu konstruk dan nilai Averege Variance Extracted (AVE) dari masingmasing konstruk. Konstruk dikatakan memiliki reabilitas yang tinggi jika nilainya 0,70 dan AVE berada di atas 0,50 pada tabel C.3 akan disajikan nilai Composite Reability dan AVE Untuk Seluruh Variabel.

Tabel C.3

Composite Reability dan Averege Variance Extracted AVE Composite Reability Avarange Variance Extracted (AVE)
Berdasarkan tabel C.3 dapat disimpulkan bahwa semua konstruk memnuhi kriteria reliabel. Hal ini ditunjukkan dengan nilai composite reliability di atas 0,70 dan AVE di atas 0,50 sebagaimana kriteria yang direkomendasikan.

Pengujian Model Struktural
Pengujian Model Atau model struktural dilakukan untuk melihat hubungan antara konstruk, nilai signifikan dan $R$-square dari model penelitian. Model struktural dengan menggunakan R-square untuk konstruk dependen uji $t$ serta dari koefisien parameter jalur struktural.

\section{Gambar 4.1}

\section{Model Strutural}

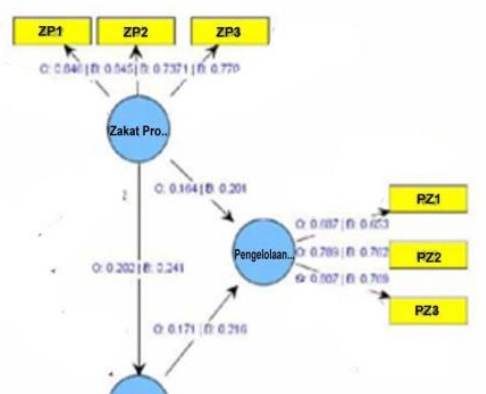


Dalam menilai Model dengan pada Tabel C.4 merupakan hasil PLS dimulai dengan melihat $R$-Square estimasi R-square dengan untuk setiap variabel laten dependen menggunakan SmartPLS

Tabel C.4

Nilai R-square

\begin{tabular}{cc}
\hline Variabel & R-square \\
\hline Zakat Profesi & 0.083 \\
\hline BAZ & 0.046 \\
\hline Pengelolaan Zakat & 0.069 \\
\hline Sumber: Pengelolaan data dengan PLS, 2015
\end{tabular}

Pada prinsipnya penelitian ini Tabel C.4 menunjukkan nilai $R$ menggunakan 3 buah variabel yang square untuk variabel Zakat Profesi dipengaruhi oleh variabel lainnya yaitu diperoleh sebesar 0,083, untuk variabel Zakat Profesi yang variabel BAZ diperoleh sebesar 0,046 dipengaruhi oleh pegawai/karyawan, dan untuk variabel Pengelolaan Zakat Variabel BAZ yang mempengaruhi oleh diperoleh sebesar 0,435. Hasil ini Zakat Profesi dan pengelolaan zakat menunjukkan bahwa $8,3 \%$ variabel yang mempengaruhi oleh BAZ. Zakat Profesi dapat di pengaruhi oleh pegawai/karyawan, 4,6\% Variabel BAZ dipengaruhi oleh variabel Zakat Profesi 
dan $6,9 \%$ variabel Pengelolaan Zakat variabel-variabel penelitian. Dasar

di pengaruhi BAZ.

\section{Pengujian Hipotesis}

Siginifikasi parameter yang memberikan output estiminasi untuk diestiminasi informasi yang sangat pengujian model struktural. yang digunakan dalam penguji hipotesis adalah nilai terdapat pada output result for inne weight. Tabel 4.5

berguna mengenai hubungan antara

Tabel C.5

For Inner Weight

\begin{tabular}{ccccc}
\hline & $\begin{array}{c}\text { original } \\
\text { sample } \\
\text { estimate }\end{array}$ & $\begin{array}{c}\text { mean of } \\
\text { subsamples }\end{array}$ & $\begin{array}{c}\text { Standard } \\
\text { deviation }\end{array}$ & $\begin{array}{c}\text { T- } \\
\text { Statistic }\end{array}$ \\
\hline $\begin{array}{c}\text { Zakat Profesi -> Pengelolaan } \\
\text { Zakat }\end{array}$ & 0.167 & 0.187 & 0.136 & 1.223 \\
\hline BAZ -> Pengelolaan Zakat & 0.164 & 0.201 & 0.192 & 0.850 \\
\hline Zakat Profesi -> BAZ & 0.215 & 0.222 & 0.165 & 1.303 \\
\hline
\end{tabular}

Dalam PLS pengujian secara statistik setiap hubungan yang dihipotesiskan dilakukan dengan menggunakan simulasi. Dalam hal ini dilakukan metode bootstrap terhadap sampel, pengujian dengan bootstrap juga dimaksudkan untuk meminimalkan masalah ketidaknomalan data penelitian. Hasil pengujian dengan bootstrapping dari analisis PLS adalah sebagai berikut :

Pengujian Hipotesis 1 (Zakat Profesi berhubungan tidak langsung dan positif terhadap Pengelolaan Zakat)
Hasil pengujian hipotesis kedua menunjukkan bahwa hubungan variabel zakat profesi dengan pengelolaan zakat menunjukkan nilai koefisien jalur sebesar 0,164 dengan $t$ sebesar 1,223. Nilai tersebut lebih kecil dari $t$ tabel $(1,308)$. Hasil ini berarti bahwa zakat profesi memiliki hubungan positif tetapi tidak signifikan terhadap pengelolaan zakat yang berarti tidak sesuai dengan hipotesis kedua dimana zakat profesi mendorong pengelolaan zakat secara langsung. Hipotesis 1 di tolak. 
Pengujian Hipotesis 2 (BAZ zakat profesi mendorong BAZ secara berhubungan tidak langsung dan langsung. Hipotesis 3 ditolak. positif terhadap Pengelolaan Zakat)

Hasil pengujian hipotesis ketiga menunjukkan bahwa hubungan variabel $B A Z$ dengan pengelolaan zakat menunjukkan nilai koefisien jalur sebesar 0.164 dengan t sebesar 0,850. Nilai tersebut lebih kecil dari $t$ tabel $(1,308)$. Hasil ini berarti bahwa BAZ memiliki hubungan positif tetapi tidak signifikan terhadap pengelolaan zakat yang berarti tidak sesuai dengan hipotesis ketiga dimana BAZ mendorong pengelolaan zakat secara tidak langsung. Hipotesis 2 di tolak

\section{Pengunjian Hipotesis 3 (Zakat Profesi berhubungan tidak langsung dan positif terhadap $B A Z$ )}

Hasil Pengujian hipotesis pertama menunjukkan bahwa hubungan variabel Zakat profesi dengan Badan Amil Zakat (BAZ) menunjukkan nilai koefisien jalur sebesar 0,215 dengan t sebesar 1.303. nilai tersebut lebih kecil dari $\mathrm{t}$ tabel $(1,308)$. Hasil ini berarti bahwa zakat Profesi memiliki hubungan yang positif tetapi tidak dignifikan terhadap Badan Amil Zakat yang berarti tidak sesuai dengan hipotetsis pertama dimana

\section{KESIMPULAN}

Seteleah melihat hasil penelitian yang telah dibahas mengenai Studi Pengelolaan Zakat Profesi Pada Badan Amil Zakat Makassar maka dapat di ambil kesimpulan sebegai berikut :

1. Ibnu Katsir menafsirkan infaq yang disebutkan dalam Q.S. al-Baqarah ayat 267 menunjukan kepada sedekah, bukan zakat, sebagaimana yang dicetuskan oleh beberapa ulama. Yusuf Al-Qardawi sangat berkeinginan agar gaji dan pemasukan dari berbagai profesi itu wajib untuk dibayarkan meski belum dimiliki selama satu haul

2. Zakat profesi adalah sejumlah harta yang dikeluarkan karena adanya hasil usaha jasa/profesi yang dimiliki yang telah mencapai haul dan nisab. Namun, berdasarkan pemaparan di atas dan pada bab sebelumnya, maka dapat disimpulkan bahwa zakat profesi itu tidak disyari'atkan dalam Islam, dan tidak dicontohkan oleh Rosulullah saw., sedangkan untuk hasil usaha jasa/profesi hanya dikeluarkan infak wajibnya saja. 
3. Pemanfaatan dana zakat yang di distribusikan masih ada yang belum tepat untuk mustahik dan pekerjaan dan profesi sangat berbeda dalam kegiatannya.

4. Dari hasil Hipotesis pertama dan keempat menunjukkan hubungan tidak langsung dan positif namun tidak signifikan antara pengelolaan zakat profesi pada badan amil zakat makassar. Hal ini berarti bahwa apa yang dicurigai tentang suatu dalam sistem pengelolaan zakat profesi pada badan amil zakat makassar itu ternyata tidak benar dengan apa yang dicurigai dan sudah tidak di permasalahkan lagi..

\section{DAFTAR PUSTAKA}

Al-Muhsun, Fakhruddin. 2011. Ensiklopedi Mini Zakat.Bogor : CV.DARUL ILMI.

Al-Qardhawi, Yusuf. Manajemen Zakat Konten Pores. Media Insani Press UUD no 38 th 1999

Anshori, Abdul Gofur. 2006. Hukum dan Pemeberdayaan Zakat : Upaya Sinegis Wajib Pajak Di Indonesia Yogyakarta : Pintar Media.

Azis, Abdul. 1996. Dahlan (editor), Ensiklopedi Hukum Islam, Jilid 6, Ichtiar baru van Hoeve, jakarta.

Departeman Agama Fiqh Zakat. Direktorat Pemberdayaan Zakat dan Direktorat Jendral Bimbingan Masyarakat Islam Kementerian Agama Republik Indonesia, 2010.

Ghozali, Imam. 2006. Structural Equation Metode Alternatif dengan partial Least Square. Edisi 2. Badan Penerbit Universitas Dipenogoro : Semarang.

Hafidhuddin, Didin. 2002. Zakat dalam Perekonomian Modern. Jakarta: Gema Insani.

Laonso, Hamid dam Muhammad Jamil. 2005. Hukum Islam Alternatif, Solusi terhadap Masalah Fiqh Kontemporer. Jakarta: Restu llahi.

Terj. Didin Hafidhuddin, et.al. 1996. Fiqhuz-Zakat. Cet. IV; Bogor: Pustaka Litera Antar Nusa.

Rauf, Abd. 2007. Fiqhi Ibadah Praktis, Makassar: Yayasan Ar-Rahmah Sulawesi.

Republik Indonesia, UU Nomor 38 Tahun 1999 tentang Pengelolaan Zakat, Lembaran Negara Republik Indonesia Tahun 1999 Nomor 164, Sekretariat Negara : Jakarta : 1999.

Al-Sayis. 1995. Pertumbuhan dan Perkembangan Hukum Fiqh Hasil Refleksi Ijtihad. Jakarta: Raja Grafindo Persada.

Syarifuddin, Amir. 1987. Pembaharuan Pemikiran dalam Hukum Islam, Jakarta:Logos.

al-Zulhaily, Wahbah. 1984. Fiqh al-Islamiy wa Adillah. Cet. 2; Damaskus: Dar alFikr. 
Zainal, Asikin dan Amiruddin. 2006. Pengantar Metode Penelitian Hukum. Jakarta: Rajawali Pers. 